\title{
Research on Cracking Sensitivity of Weathering Steel SMA490BW
}

\author{
Xiangyang $\mathrm{Wu}$ \\ CSR SIFANG Co.,Ltd \\ Qingdao, China \\ sfxiangyangw@163.com \\ Zhiyi Zhang \\ CSR SIFANG Co.,Ltd \\ Qingdao, China \\ yefan_0954@163.com \\ Wen Li \\ CSR SIFANG Co.,Ltd \\ Qingdao, China \\ 13969870187@163.com
}

\author{
Yongjing Wang \\ Institute of Materials Science and Engineering, Xihua \\ University \\ Chengdu, China \\ 892238201@qq.com \\ Yue Liu \\ Institute of Materials Science and Engineering, \\ Southwest Jiaotong University, Chengdu, 610031, P.R \\ China \\ 285017979@qq.com
}

\begin{abstract}
SMA490BW is used specifically for the manufacture of welded frame of high-speed EMU bogies. Bogie is one of a very important bearer units and transmission units during driving while bogie frame is one of the most important bearer units and transmission units in bogie, directly related to safety during driving. So it's necessary to study on the cracking sensitivity of the materials. Fracture toughness is the basic data in researching the cracking sensitivity of materials in fracture mechanics. This article employs three-point bending test method to test the fracture toughness $\mathrm{Kc}$ of weathering steel SMA490BW in plane stress state. Observe the microstructure of SMA490BW by Metallurgical microscope and scan the fracture morphology of the three-point bending specimens by SEM. The results show that for $12 \mathrm{~mm}$ thick metal, the fracture toughness $\mathrm{Kc}$ of SMA490BW is $\mathrm{K}_{\mathrm{C}}=2504.66 \mathrm{MPa} \cdot \mathrm{mm}^{1 / 2}$. The microstructure is small ferrite and strip pearlite. In addition, the fracture of the three-point bending specimen is flat, and the brittle fracture zone is of uniform micro granular. It is a pure plane strain brittle fracture.
\end{abstract}

Keyword: SMA490BW;Three-point bending test; Fracture morphology; Fracture toughness Kc; cracking sensitivity

\section{INTRODUCTION}

The fracture of the components origins in cracks. And the static, balance or development of cracks is directly related to the stress field near the crack tip. Around 1957, through an analysis near the mode I crack-tip stress field by elastic methods, Owen introduced a new parameter $\mathrm{K}$-stress intensity factor. He defined the concept of fracture toughness on the basis of $\mathrm{K}$ and proposed the fracture criterion. At the same time, he established the material fracture toughness measurement method which laid the theoretical foundation of linear elastic fracture mechanics [1]. Mode I crack under uniaxial tension is the most common crack in engineering. $\mathrm{K}_{\mathrm{C}}$ is the fracture toughness for mode I crack under plane stress conditions, which could express the materials' ability to resist the instability and growth of cracks under plane stress conditions. Weathering Steel SMA490BW has high mechanical properties such as strength, ductility and toughness, and also has a good resistance to atmospheric corrosion. It's used specifically for the manufacture of welded frame of high-speed EMU bogies ${ }^{[2,3]}$. Bogie frame is usually a welded structure and welded structures are generally difficult to guarantee its completeness ${ }^{[4]}$.The strength of frame is directly related to safety ${ }^{[5,6]}$. So it's of great importance to study on the cracking sensitivity of SMA490BW. This article chooses the CTOD (Crack Opening Displacement) method which can keep the actual size of the materials and has great advantages to evaluate the cracking sensitivity ${ }^{[7,8]}$. Then use some formulas between the results of CTOD test and the fracture toughness $\mathrm{Kc}$ to obtain the final conclusion. We employ three-point bending test method to test the fracture toughness Kc of weathering steel SMA490BW according to GB/t 21143-2007 Metallic materials-Unified method of test for determination of quasistatic fracture toughness ${ }^{[9]}$ and analyses its resistance to cracking susceptibility via observing the microstructure of SMA490BW and bending fracture.

\section{EXPERIMENTAL MATERIALS AND DETAILS:}

Wherever Times is specified, Times Roman or Times New Roman may be used. If neither is available on your word processor, please use the font closest in appearance to Times. Avoid using bit-mapped fonts if possible. TrueType 1 or Open Type fonts are preferred. Please embed symbol fonts, as well, for math, etc. 

object. Its chemical composition shows in Table I and its mechanical properties shows in Table II.

TABLE I. CHEMICAL COMPOSITION OF SMA490BW（WT\%）

\begin{tabular}{|c|c|c|c|c|c|c|c|c|c|}
\hline Grades & $\mathbf{C}$ & $\mathbf{S i}$ & Mn & $\mathbf{S}$ & $\mathbf{P}$ & $\mathrm{Cr}$ & $\mathbf{N i}$ & $\mathbf{C u}$ & notes \\
\hline \multirow[t]{4}{*}{$\begin{array}{c}\text { SMA490 } \\
\text { BW }\end{array}$} & $\leq 0.18$ & $\begin{array}{c}0.15 \sim \\
0.65\end{array}$ & $\leq 1.40$ & $\leq 0.0050$ & $\leq 0.035$ & $\begin{array}{c}0.45 \sim \\
0.75\end{array}$ & $\begin{array}{c}0.05 \sim \\
0.30\end{array}$ & $\begin{array}{c}0.30 \sim \\
0.50\end{array}$ & $\begin{array}{l}\text { standard } \\
\text { value }\end{array}$ \\
\hline & \multicolumn{9}{|c|}{ IANICAL PROPERTIES OF SMA490BW } \\
\hline & \multicolumn{2}{|l|}{ Grades } & \multicolumn{2}{|c|}{$\begin{array}{c}\text { Yield strength } \\
(\mathrm{MPa})\end{array}$} & \multicolumn{3}{|c|}{$\begin{array}{c}\text { Tensile strength } \\
\text { (MPa) }\end{array}$} & \multicolumn{2}{|c|}{ Young's modulus (GPa) } \\
\hline & \multicolumn{2}{|l|}{ SMA490BW } & \multicolumn{2}{|c|}{446} & \multicolumn{3}{|c|}{604} & \multicolumn{2}{|c|}{201} \\
\hline
\end{tabular}

\section{B. Experimental Methods :}

Specimens in the size of $10 \mathrm{~mm} \times 10 \mathrm{~mm} \times 12 \mathrm{~mm}$ should be cut by the wire cutting machine and prepared as metallographic specimens. Corrode these metallographic specimens with $4 \%$ nitric acid alcohol solution and observe the microstructure under OLYMPUS-TOKYO optical microscope. Then do the three-point bending test with CMT-4304 electronic universal testing machine. The size and shape of the specimens is shown in Fig. 1. Firstly, make a fatigue precrack $2-3 \mathrm{~mm}$ with tuning fork fatigue slotted machine ${ }^{[10]}$. Then use complete loading by $30 \mathrm{KN}$ electronic universal testing machine (CMT-4304) until the plastic instability with the loading rate for $1.0 \mathrm{~mm} / \mathrm{min}$. Test procedures are automatically recorded in the $\mathrm{P}-\mathrm{V}$ curve. Remove the specimens and carry oxidation treatment on the fracture surface after loading so that the regions of plastic deformation and fatigue crack growth zone can be distinguished. Put the specimens into the dry ice for about 5 minutes to reduce their plastic after the discoloration on the fracture surface and then press them rapidly on the electronic universal testing machine. Measure these specimens' initial crack length $a_{0}$ with XTL-340E Stereoscopic Microscopes. Cut off the fracture and scan the fracture morphology by SEM.

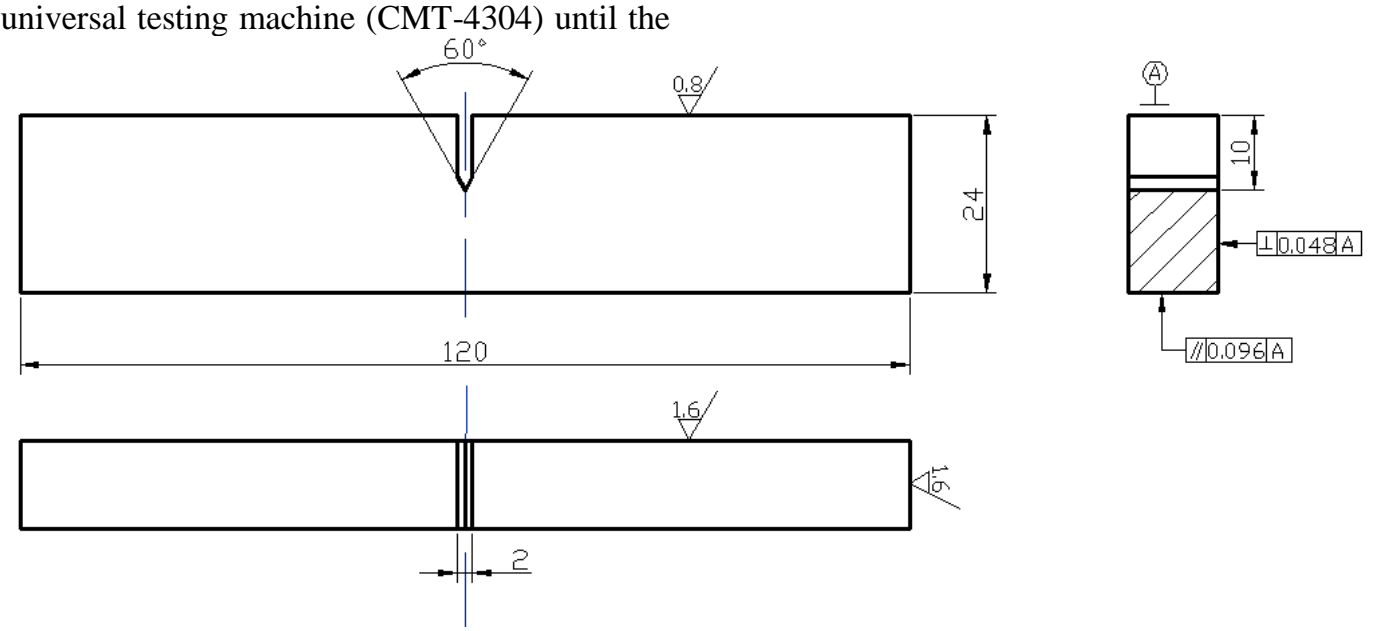

Figure 1. The shape and size of three-point bending specimens

\section{EXPERIMENTAL RESULTS AND DISCUSSION:}

\section{A. Microstructure}

The microstructure morphology of low alloy high strength steel SMA490BW is in Fig. 2. We can see from the figure that the microstructure is rolling, made up of ferrite and Pearlite. The Pearlite is of stripy distribution. Part of the morphology produces Pearlite structure segregation and the grain of ferrite is small. The material has homogeneous microstructure.

\section{B. Fracture morphology}

The macroscopic fracture of the three-point bending specimens shows in Fig. 3:

I is the mechanical notch zone. II is the prefabricated fatigue crack zone. III is the fatigue crack propagation zone and IV is the brittle fracture zone. The boundaries of these zones are clear. The frontier of the fatigue crack is bending slightly symmetrically. The SEM fracture morphology shows in Fig. 3-3. We can see from the figure that cracks soon reaches a critical size while the quick bending process. Then low energy tears occur in the specimens. The macroscopic morphology of the fracture surface is flat and is of radiating pattern which is the 
caused by shear deformation of metals. The brittle fracture zone is of uniform micro granular. The boundaries of mechanical notch, fatigue crack propagation zone and brittle fracture zone are clear. The frontier of the fatigue crack is bending slightly symmetrically. We can observe the thin layer shear lips with smooth surface on both sides of the brittle fracture zone under microscope. The micromorphology of the fracture surface is of fan-shaped pattern and is obvious cleavage fracture. (showed in Fig.4ab ) The fracture has obvious characteristics of brittle fracture with pre-processing in dry ice. The process storing the specimens in dry ice could reduce the plastic of the metals and prevent the errors during measuring the length of cracks from oversized plastic deformation. In addition, the secondary cracks were mainly originated from inclusions positions.

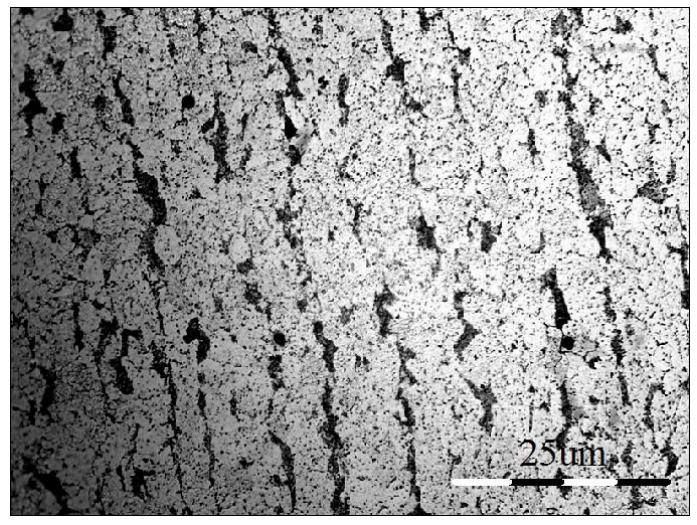

Figure 2. The microstructure morphology of SMA490BW

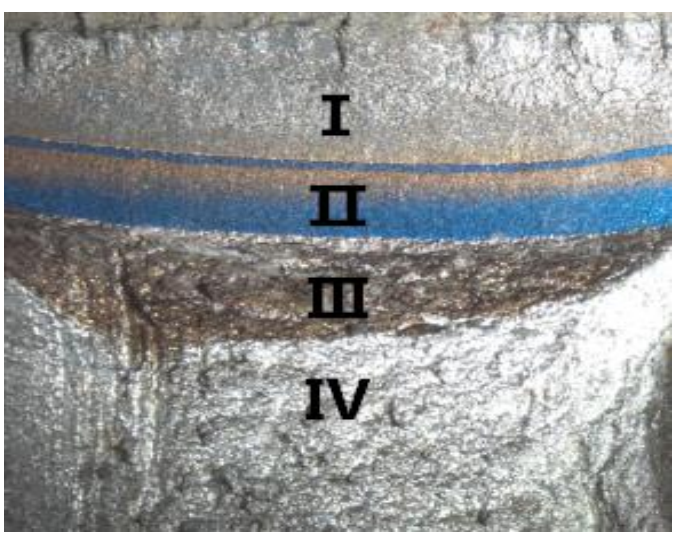

Figure 3. The macroscopic fracture of the three-point bending specimens

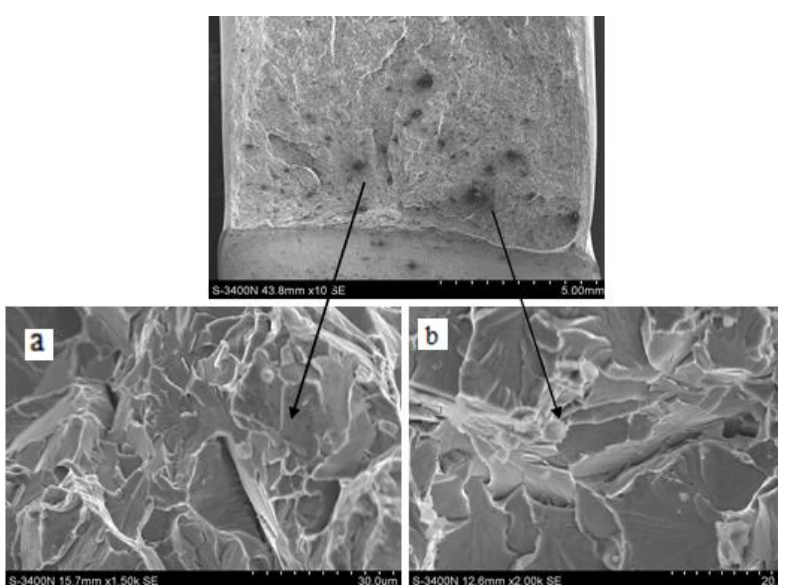

Figure 4. The SEM fracture morphology of the three-point bending specimens

\section{The results of three-point bending test}

Draw P-V curve (showed in Fig. 5) according to the corresponding relationship between notch opening displacement $(\mathrm{V})$ and loading $(\mathrm{P})$. Point $\mathrm{A}$ on the curve is the elastic-plastic transition point.

$$
\begin{aligned}
& W=\frac{W_{1}+W_{2}+W_{3}}{3}=24.20 \mathrm{~mm} \\
& B=\frac{B_{1}+B_{2}+B_{3}}{3}=12.14 \mathrm{~mm}
\end{aligned}
$$

$\mathrm{P}_{\mathrm{c}}=9049.44 \mathrm{~N}, \mathrm{~V}_{\mathrm{c}}=0.36 \mathrm{~mm}$.

The value of $\mathrm{a}_{0}$ is 13.02 through measurement.

\section{Solving the fracture toughness}

The deformation of the three-point bending specimens can be seen as a rigid rotation which rotates around a central point (ex. Point $\mathrm{C}$ in Fig. 6) to the bending moment. The distance from the Point $\mathrm{C}$ to the crack-tip is $\mathrm{r}(\mathrm{W}-\mathrm{a})$, where $r$ is the rotational factor. The relationship between crack opening displacement $(\delta)$ and notch opening displacement $(\mathrm{V})$ can be exported by the similar triangle principle:

$$
\delta=\frac{\mathrm{r}\left(W-a_{0}\right) V}{Z+a_{0}+r\left(W-a_{0}\right)}
$$

Where:

$\mathrm{Z}$ is the thickness of the cut; $\mathrm{a}_{\mathrm{o}}$ is the depth of the initial crack; $\mathrm{W}$ is the width of the specimens; $r$ is the rotational factor.

Under critical state:

$$
\delta_{c}=\frac{\mathrm{r}\left(W-a_{0}\right) V_{c}}{Z+a_{0}+r\left(W-a_{0}\right)}
$$

Where $\mathrm{V}_{\mathrm{C}}$ is the critical notch opening displacement.

It's obviously from this formula that $\delta \mathrm{c}$ is obtained if we can read out $V_{C}$ on the P-V curve and determine the rotation factor $r$. According to the GB of CTOD, the $r$ is 0.45 and $\mathrm{V}_{\mathrm{C}}$ is $0.36 \mathrm{~mm}$.

\section{So:}

$$
\delta_{c}=\frac{0.45 \times(24.20-13.02) \times 0.36}{2+13.02+0.45 \times(24.20-13.02)}=0.0891 \mathrm{~mm}
$$

Then according to the relationship between critical crack tip opening displacement and stress intensity factor:

$$
\delta_{C}=\frac{4 K_{C}{ }^{2}}{\pi \sigma_{S} E}
$$




$$
K_{C}=\sqrt{\frac{\pi \sigma_{S} E \delta_{C}}{4}}
$$

Where:

$\sigma_{\mathrm{s}}$ is the yield strength of the materials; $\mathrm{E}$ is the Young's modulus.

Putting the data in the formula, the result we calculated is $\mathrm{K}_{\mathrm{C}}=2504.66 \mathrm{MPa} \cdot \mathrm{mm}^{1 / 2}$.

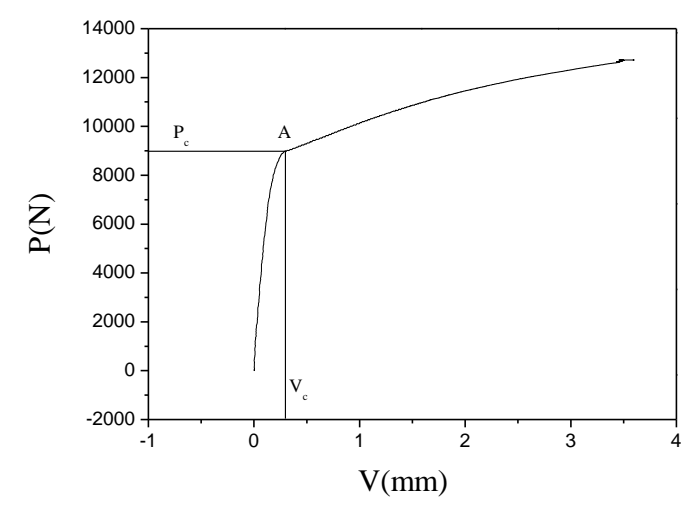

Figure 5. P-V curve

\section{E. The analysis of cracking sensitivity}

For the most part, people study on the cold cracking susceptibility of materials when they want to obtain the cracking susceptibility. Fracture toughness performs as the parameter to evaluate the ability of material to resist fracture. It depends on internal factors such as the chemical composition of materials, organizational structure, but also the influence of temperature and strain rate.

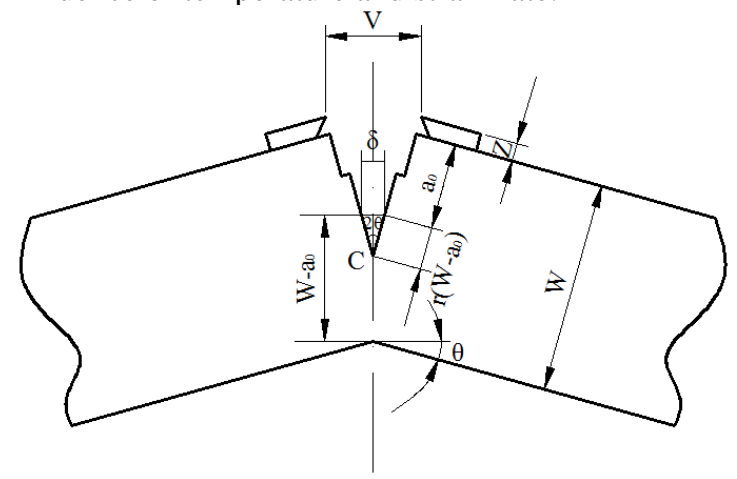

Figure 6. The relationship between $\delta$ and $\mathrm{V}$

SMA490BW for this test is rolling, made up by small ferrite and Pearlite. It has uniform composition. The strength and fracture toughness of the material are increased due to fine grain strengthening effect.

Carbon is the main element affecting the hardenability of materials. We choose the formula to calculate the carbon equivalent of SMA490BW recommended by IIW :

$$
\mathrm{C}_{\mathrm{eq}}=w(\mathrm{C})+\frac{w(\mathrm{Mn})}{6}+\frac{w(\mathrm{Cr})+w(\mathrm{Mo})+w(\mathrm{~V})}{5}+\frac{w(\mathrm{Ni})+w(\mathrm{Cu})}{15}
$$

The carbon equivalent is about $0.36 \%$ through calculation. It is now generally granted that the material has poor performance in welding if its carbon equivalent is greater than $0.45 \%$. So the harden quenching tendency of material SMA490BW is small, which shows the tendency of cold cracking is small.

\section{CONCLUSION:}

1) The microstructure of SMA490BW is rolling, made up of small ferrite and Pearlite. The Pearlite is of stripy distribution. The fine grain strengthening effect could reduce its cold cracking susceptibility.

2) Through three-point bending test, we tested the fracture toughness $\mathrm{Kc}$ in the plane stress state. The results show that for $12 \mathrm{~mm}$ thick metal, $\mathrm{K}_{\mathrm{C}}$ is 2504.66MPa $\cdot \mathrm{mm}^{1 / 2}$.

3) The fracture of the three-point bending specimen is flat, and the brittle fracture zone is of uniform micro granular. It is a pure plane strain brittle fracture. The boundaries of mechanical notch, fatigue crack propagation zone and brittle fracture zone are clear. The frontier of the fatigue crack is bending slightly symmetrically. We can observe the thin layer shear lips on both sides of the brittle fracture zone under microscope.

\section{REFERENCE:}

[1] Wu Ying. Fracture and Fatigue [M]. Wuhan : China University of Geosciences press, 2008.

[2] Li Dandan, Zhang Zhiyi, Shi Chunyuan. The influence on impact properties of SMA490BW welded overheated zone by multiple repairing welding $[\mathrm{J}]$. Thermal processing technology. 2011, 40 (17), 161-166.

[3] Qi Weichuang, Zhang Zhiyi, Sun Weiming. The study on the CCT curve of SMA490BWsteel[J]. Rolling process,2012(4):24-26.

[4] Zhang Yanhua. Fitness for Service Assessment of Welded Structures[J]. Aeronautical manufacturing technology,2011(11):5456.

[5] Li Baorui. Strength analysis for powered bogie welded frame of CRH2 type motor unit.[D]. Tianjin University, master of science.2012:1

[6] SH IMIZU K, TORII T, MA Y. Crack opening sliding morphology and stress intensity factor of slant fatigue crack[J].Key Engineering Materials, 2005 (297 - 300) : 697 - 702.

[7] Tian Yue. The fracture toughness assessment method of bridge steel with CTOD and BS 7910 [J]. China railway science, 2010(2):40-44.

[8] Xia Ziyu.Experimental study on the effects of welded joints microstructure on CTOD of High-strength steel and flaws assessment based on BS7910[D]. Wuhan University of technology.

[9] GB/T 21143-2007. Metallic materials-Unified method of test for determination of quasistatic fracture toughness. [S].

[10] Yao Mei. Double elastic parts fork fatigue slitting machine [J] Equipment and instrument,1985(1):43-45. 